\title{
GCU
}

Glasgow Caledonian

University

University for the Common Good

\section{The quality of bioethics debate: implications for clinical ethics committees}

\section{Williamson, Laura}

Published in:

Journal of Medical Ethics

DOI:

10.1136/jme.2007.021634

Publication date:

2008

Document Version

Author accepted manuscript

Link to publication in ResearchOnline

Citation for published version (Harvard):

Williamson, $L$ 2008, 'The quality of bioethics debate: implications for clinical ethics committees', Journal of Medical Ethics, vol. 34, no. 5, pp. 357-360. https://doi.org/10.1136/jme.2007.021634

\section{General rights}

Copyright and moral rights for the publications made accessible in the public portal are retained by the authors and/or other copyright owners and it is a condition of accessing publications that users recognise and abide by the legal requirements associated with these rights.

Take down policy

If you believe that this document breaches copyright please view our takedown policy at https://edshare.gcu.ac.uk/id/eprint/5179 for details of how to contact us. 


\section{The Quality of Bioethics Debate: Implications for Clinical Ethics Committees}

Dr Laura Williamson

Research Fellow in Health Ethics

Institute of Law and Ethics in Medicine

University of Glasgow

8 The Square

Glasgow

G12 8QQ

L.Williamson@law.gla.ac.uk

Office: 01413302405

Fax: 01413304698

Keywords: Bioethics, Clinical Ethics, Clinical Ethics Committees

Word Count: 3,490

\section{Competing Interests: None}

Acknowledgements: I am grateful to Professor Sheila McLean and Professor Udo Schuklenk for their comments on an earlier version of the manuscript.

Funding: Research for this paper was conducted as part of a project funded by the Wellcome Trust (ref. 07446) entitled 'Ethico-Legal Governance in Health Care'.

"The Corresponding Author has the right to grant on behalf of all authors and does grant on behalf of all authors, an exclusive licence (or non exclusive for government employees) on a worldwide basis to the BMJ Publishing Group Ltd and its Licensees to permit this article (if accepted) to be published in JME editions and any other BMJPGL products to exploit all subsidiary rights, as set out in our licence (http://jme.bmjjournals.com/ifora/licence.dtl)." 


\title{
The Quality of Bioethics Debate: Implications for Clinical Ethics Committees
}

\begin{abstract}
Bioethicists have recently expressed concern over a lack of quality control within the field. This apprehension focuses on bioethics expanding in ways that obscure its distinctive ethical remit and the specialist reasoning skills it requires. This thesis about the quality and conduct of bioethics may have particular relevance for clinical ethics. As one of the youngest offshoots of bioethics, the field focuses on the ethical issues that arise specifically in a clinical context. However, nonethics specialists are increasingly involved in this field. This means that clinical ethics could be especially vulnerable to the quality control concerns articulated within bioethics. The growing public profile of clinical ethics means that concerns over quality in this area warrant specific attention by those concerned with declining standards in bioethics and those working in clinical ethics.
\end{abstract}

\section{Quality in Bioethics}

A number of bioethics specialists have recently articulated concerns over a lack of quality control within the field. ${ }^{1-2}$ Attention has focussed on the implications of viewing bioethics as such a capacious discipline that its philosophical (ethical) roots and so its quality, are compromised. It is claimed, for example, that once disciplines like medical sociology and law are taken to be an integral part of bioethics, there can be confusion over issues such as the relationship between legal and ethical thought and difficulty distinguishing between description and prescription. Those who have expressed concern 
about quality in bioethics are not denying the need to inform ethical analysis by drawing on the insights of other disciplines or the methodological rigor of such disciplines. Rather, effort is being made to emphasise the distinctive nature of bioethics; namely, its focus on '... advancing and examining arguments about what ought, morally, to be done and not done - about what is (actually, rather than merely thought to be) right and wrong. ${ }^{\prime 1}$

The problems associated with understanding bioethics as a broad discipline are, it is claimed, compounded by a one-way 'disciplinary slip' that leads to the acceptance of experts in other disciplines working in bioethics without sufficient training in the philosophical methods required to perform ethical analysis in a sophisticated manner. Benatar explains that this problem is influenced by the fact that the expertise of philosophers is frequently undervalued. In this respect, the increasing importance of bioethics to professionals in other fields actually spurs the decline in standards. This, Benatar suggests, is because the growing interest in bioethics is rarely filled by those who are actually bioethics specialists, but by a band of often selfappointed ethics 'experts' drawn from an array of other specialisms. ${ }^{1}$

The decline in bioethics quality, it is suggested, is occurring in both publication and pedagogy. In respect of publication, papers with significant bioethics components appear in the professional journals of disciplines that rarely have their ethical content assessed by those with philosophical training; 
and journals dedicated to ethics increasingly contain surveys with very little, if any ethics. ${ }^{1-2}$ In terms of pedagogy, the desire of, for example, healthcare professionals to acquire training in bioethics means that '... the audience for much bioethics writing and talk are people who, because they are not trained in philosophy, are much less discerning about what constitutes good philosophy'. ${ }^{1}$ As Benatar laments '... a brief course or diploma is thought sufficient to transform a novice into a so-called "ethicist", "bioethicist" or, worse still, a bioethics educator' ${ }^{\prime}{ }^{1}$ Together, these concerns lead to fears that the failure to ground bioethics sufficiently in philosophical ethics will result in an empty brand of 'non-ethics bioethics'.2

These recent comments about quality in bioethics are part of debates on ethical expertise and the relationship between ethics and disciplines such as social science. ${ }^{3}$ Yet reading these concerns about the quality, conduct and integrity of ethics in the context of initiatives to help support clinical ethics in the United Kingdom (UK) gives such issues added significance.

Within the UK, clinical ethics committees (CECs) represent an increasingly popular way of responding to ethical issues within clinical care. ${ }^{4}$ If the growth of CECs continues, they and clinical ethics may become the form of bioethics with the greatest civic influence. Indeed, support for committees is growing in the UK despite caveats over their performance. ${ }^{5-6}$ Questions about the value and quality of ethics services raised in the UK are part of larger international 
debates..$^{7-8}$ This paper will investigate how concerns regarding quality in bioethics apply to clinical ethics and CECs and consider the implications of these issues for the development of ethics services in the UK.

\section{Clinical Ethics: Its Nature and Aims}

Clinical ethics is a relatively recent offshoot of bioethics. ${ }^{9-10}$ The field emerged from a move within bioethics to respond directly to the challenge of doing 'ethics at the bedside' ${ }^{11}$ Fletcher and Siegler have summarised the central goals of the field thus: facilitating the resolution of conflicts by identifying and supporting the 'interests, rights and responsibilities of those involved'; helping to generate policies and practices 'consistent with ethical norms and standards'; and helping individuals address 'ethical problems by providing education in healthcare ethics'.$^{12}$ More simply, clinical ethics services tend to divide their time between three enterprises: case consultation, policy advice and education (both self-education, and training of those external to the committee) $\cdot^{13-14}$

The issues examined within clinical ethics and by CECs are those traditionally associated with medical ethics including: consent, competency, the distribution of resources, decisions regarding treatment at the beginning and end of life and genetic testing. The distinctive identity of clinical ethics comes 
from the environment in which it takes place and the way in which it juxtaposes clinical and ethical skills. As Fletcher et al. note:

For the word ethics in its name to ring true, clinical ethics must authentically bridge between the clinical world and the theoretical disciplines of bioethics and medical humanities in the academic world.... ${ }^{15}$

Given that accurate empirical data plays a key role within applied ethics, it would be easy to assume that efforts to bridge between clinical practice and ethical theory are easily accomplished. Yet the identity of clinical ethics is, as Jonsen has stated, ambiguous. ${ }^{16}$ This ambiguity means that clinical ethics tends to be regarded as either a medical discipline conducted by healthcare professionals, or a theoretical enterprise staffed by philosophers and theologians. ${ }^{16}$ When it is associated primarily with healthcare its ethical credentials become dubious. The field has, for example, been described as a 'branch of medicine'. ${ }^{17}$ Similar characterisations include claims that: 'the field of biomedical ethics, now has a clinical discipline (ethics consultation) $)^{\prime} ;^{18}$ and 'clinical ethics is a field of expertise in healthcare, rather than a separate field, discipline or profession' ${ }^{19}$ It is questionable whether accounts of clinical ethics that identify it primarily as a clinical practice will give sufficient attention to the ethical methods that should also be at the heart of such work. As a result conceptualising clinical ethics as a medical discipline may have a detrimental impact on its ethical identity and quality. 
Another possible outcome of viewing clinical ethics as a medical discipline is that ethical issues will not be identified or addressed at all. As Murray has stated in relation to the situation in the United States:

... 'ethics' per se does not have a primary role in committee discussions of concrete cases. It is commonly said that clarifying the facts and fostering communication comprise upwards of 80 to 90 percent of their work..$^{20}$

However, if ethics committees operate under the false assumption that their role is accomplished by addressing such issues, then ethical issues they were formed to address are unlikely to receive the attention they merit. As a result the quality of care provided may be undermined if the ethical interests of patients and professionals are overlooked by the services intended to protect them.

The concerns over the issues and approaches that are used within clinical ethics also extend to research in the field. Singer, Siegler and Pellegrino have identified that clinical ethics research tends to be either theoretical or empirical in nature. ${ }^{21}$ Theoretical research 'employs the methods of logical reasoning and argument. It is founded on the principles of philosophical and theological ethics, law, or public policy..21 This description of theoretical research includes methods of working associated with health ethics. The same is not true of empirical clinical ethics research that uses '... methods of the 
social sciences, decision analysis, clinical epidemiology, and health services research...' 21

Empirical data is imperative to informed ethical analysis. This leads publications like the Journal of Medical Ethics to publish a high percentage of empirically based studies within its section dedicated to 'clinical ethics'. Empirical studies play an important role in helping to identify how CECs are developing and the issues that dominate the field of clinical ethics, such as the type of work that occupies clinical ethicists, their subject specialisms and their

level of ethical training. ${ }^{4}$ That said, analysis based on social science methods is not itself a form of ethical reasoning, so taking empirical research to be a part of clinical ethics risks creating confusion over the goals of the field.

The medico-empirical focus of some accounts of clinical ethics and ethics consultation appear, perhaps inadvertently, to sanction the 'disciplinary slip' identified within bioethics. ${ }^{1-2}$ This concern over the ethical content and quality of clinical ethics is greatly influenced by who is responsible for conducting such work.

\section{Clinical Ethics: Its Practitioners}

Jonsen explains that clinical ethics emerged in the United States from the perception of medics and 'physician-educators' that clinical work could benefit from engaging directly with whose primary training was in 
theological or philosophical ethics. ${ }^{16}$ The immersion of professional ethicists in clinical environments is reported to have created discomfort amongst these philosophical trail-blazers, as one remarks:

Our reaction often was that this is simply no place for a philosopher, whose training and disposition include nothing that could prepare one for rendering judgments, much less definitive, possibly irreversible, moral decisions. ${ }^{22}$

At the same time as philosophers were being invited to work on real ethical issues within clinical settings, healthcare professionals were also trying to get to grips with ethics themselves so they could address the dilemmas that they faced on a day-to-day basis. Sulmasy explains that while medical ethics is thought to have emerged in the 1960s:

... truly clinical ethics began later, as the philosophers and theologians moved into the professional schools, onto the wards, and into the clinics. Clinical ethics also emerged as clinicians themselves began to pursue training and education in ethics, began to teach, do research, perform consults... ${ }^{23}$

As clinical ethics resources have developed in the US, professional ethicists and healthcare professionals have come to staff a variety of services. There are full multidisciplinary ethics committees, small 'quick-response' emergency teams - perhaps part of a larger committee - individual ethics consultants (usually professional ethicists) and no doubt other manifestations that fulfil local needs. Similar developments have occurred in the UK, although it seems 
that the primary - though not exclusive - form of ethics consultation service is the multidisciplinary committee. ${ }^{4}$ The development of such committees has been perceived as way to provide the wide-range of expertise needed to address ethical dilemmas within clinical care. In order for ethical issues to be identified and addressed in a sophisticated manner by CECs, ethical skills must be sufficiently represented amongst the members of such committees.

A number of empirical studies have examined the constitution of CECs in both the US and UK and found a low percentage of committee members are ethics specialists. The same studies have also found relatively low levels of ethics training amongst members with a different subject specialism. ${ }^{4}$, 24-26 Furthermore, Benatar's concerns about the short training programmes that litter the field of bioethics are also relevant within clinical ethics. ${ }^{1}$ The growth of 'kwik-fit' clinical ethics courses targeted at the members of CECs, risk giving insufficient training to equip professionals with adequate analytical skills for their role on committees. ${ }^{27}$ In addition, they give the impression that clinical ethics - and perhaps health ethics more generally - is a discipline that can be taught easily and quickly, so underestimating the skills required. ${ }^{1}$

Clinical ethics committees epitomize the broad, multidisciplinary brand of ethics - often performed by non-ethics specialists - that bioethicists have critiqued for its poor quality. ${ }^{1-2}$ As a result committees may not be equipped to perform the increasingly prominent role they have within health ethics. CECs 
must take greater account of the ethics specialisation required by their remit. In this respect it appears indisputable that philosophical ethics should have a prominent role within this work. However, the very development of CECs suggests that other, more philosophical expressions of health ethics (including bioethics) are not perceived as providing an adequate response to the ethical issues that arise in clinical care. This raises questions over the assumption that philosophy provides the solution to quality concerns in bioethics and the work of CECs.

\section{The Pursuit of Ethical Quality: The Role of Philosophical Ethics}

Doubts have been expressed within philosophy over the ability of philosophical ethics to provide an adequate response to practical dilemmas within healthcare. ${ }^{28-30}$ Beauchamp, for example, has suggested that rather than being closely connected, the relationship between bioethics and moral theory is 'contingent and fragile'.${ }^{29}$ Given the greater practical focus of clinical ethics, its relationship with moral theory will arguably be even more tenuous. The practical abilities of bioethics have also been criticised by social scientists who contend that this 'purportedly interdisciplinary' field has often overemphasised the importance of philosophical skills. ${ }^{3}$ More specifically, it is claimed that bioethics is over reliant on abstract, idealised reasoning and, therefore, gives insufficient attention to the practical and socio-cultural dimensions of contemporary ethical dilemmas. ${ }^{31}$ 
This widespread concern over the practical abilities of philosophy suggests that calls to place 'good philosophy' at the heart of applied ethics to improve its quality may not be good enough when it comes to responding to practical dilemmas in clinical care. Thus, ways must be found to integrate ethics specialisation more successfully within interdisciplinary exchanges without allowing bioethics to become and even greater free for all. To secure a more consistent commitment to ethics specialisation it is important for ethicists to clearly articulate that the role of ethical analysis is to test the consistency of arguments and identify flawed logic or dubious premises as part of its pursuit to determine the right or best way for humans to live. This is because one of the greatest obstacles to the quality of ethical work in healthcare is that its very nature and aims are misunderstood by other disciplines. In this respect, clinical ethics is particularly badly affected and social scientists have been key offenders.

De Vries, for example, argues that social science '... allows bioethicists to see if their contributions to the biosciences are making a difference, if bioethics measured on its own terms - is a success. ${ }^{32}$ To illustrate how social science performs this important role De Vries points to studies that employ criteria such as user satisfaction and the reduction of non-beneficial treatment to help gauge the success of ethics services. ${ }^{33},{ }^{34}$ Although it is admittedly important that service users are happy with the service they receive from a CEC - or 
they may not use it, or recommend it in the future - satisfaction is not a safe measure of ethical quality. High levels of satisfaction may, for example, signify no more that medics or patients getting their own way due to the impotence of a CEC. There are also problems with the way other empirical measures, such as the reduction of non-beneficial treatment and quantity, assess ethics. ${ }^{35}$

De Vries and the authors of such studies fail to appreciate that these empirical outcome measures are not in fact measuring ethics 'on its own terms', but essentially miscast ethics as an empirical discipline. It is ironic that De Vries claims that these social science studies produce 'friendly, useful criticism' that shows ethics services 'do not have the desired effect' so resulting in the 'implicit criticism of bioethics' ${ }^{32}$ In fact the studies have little to say about bioethics because their inaccurate characterisation of it means this is not what they are assessing. While critiques of bioethics are so misguided it is difficult to see how the need for ethics expertise can be seriously resisted.

\section{Conclusion}

It would be unfortunate if the multidisciplinary constitution of CECs automatically leads to such bodies being censured for their dubious ethical credentials. To avoid this charge, committees must prioritise their pursuit and maintenance of ethics training. This will involve ethics services and ethicists 
working together to create training programmes that are more substantial, robust and beneficial to the day-to-day work of CECs. It must be constantly borne in mind that committees are not just a forum for discussing the facts of a particular case and the normative values that surround it, but must also have critical teeth to allow them to dissect flawed reasoning that may be used (perhaps inadvertently) either to support bad practice or to prevent much needed developments within clinical practice. To fulfil these tasks ethical and not only empirical training is required.

Instead of comfortably stating and restating doubts about the ethical abilities of non-specialists in bioethics and CECs, ethicists must find ways to promote (and protect) the role their discipline has to play in clinical environments and civic life. In this respect, ethicists must champion their discipline by fearlessly seeking to enable other willing-hands to 'do' ethics in a manner that can influence practice. The only form of ethical protectionism suited to our times is that of genuine engagement and facilitation.

\footnotetext{
${ }^{1}$ Benatar D, Bioethics and Health and Human Rights: A Critical View. Journal of Medical Ethics, 2006 32, 17-20.

${ }^{2}$ Schuklenk U, Ethics in Bioethics. Bioethics, 2006 20, 5, iii.

${ }^{3}$ Fox R, Swazey J, Examining American Bioethics: Its Problems and Prospects, Cambridge Quarterly of Healthcare Ethics, 2005 14, 361-373.

${ }^{4}$ Slowther A, Bunch C, Woolnough B, Hope T, Clinical Ethics Support in the UK: A Review of the Current Position and Likely Development. London: Nuffield Trust; 2001.

${ }^{5}$ Nuffield Council on Bioethics, Critical Care Decisions in Fetal and Neonatal Medicine: Ethical Issues, London: Nuffield; 2006.

${ }^{6}$ Royal College of Physicians, Ethics in Practice: Background and Recommendations for Enhanced Support, London: RCP; 2005.

${ }^{7}$ Brennan TA, Quality of Clinical Ethics Consultation. Quality Review Bulletin 1992, 18, 1, 4-5.
} 
${ }^{8}$ Wolf S.M. Quality Assessment of Ethics in Health Care: The Accountability Revolution American Journal of Law and Medicine 1994, 20, 105-128;

9 Callahan, D, Bioethics Encyclopedia of Bioethics, Post, S.G., (ed)., 278-287 New York: Macmillan, 2004, Third Edition.

${ }^{10}$ Rubin SB, Zoloth L, Clinical Ethics ad the Road Less Taken: Mapping the Future by

Tracking the Past Journal of Law, Medicine \& Ethics 2004, 32, 218-225, at p. 218

${ }^{11}$ Childress JF, Foreword in Introduction of Clinical Ethics, Fletcher JC, et al., (ed), iiv,

Maryland: University Publishing Group; 1997, (Second Edition)

${ }^{12}$ Fletcher JC, Siegler M, What are the Goals of Ethics Consultation? A Consensus Statement Journal of Clinical Ethics 1996, 7, 2 122-126, at p. 125.

${ }^{13}$ Ross JW, Glaser JW, et al., Health Care Ethics Committees The Next Generation, Il: American Hospital Publishing, 1993.

${ }^{14}$ Dougherty CJ, Clinical Ethics: Institutional Ethics Committees in Encyclopedia of Bioethics, Post, S,(ed), 444-447, New York: Macmillan Reference; 2004.

${ }^{15}$ Fletcher JC, Miller FG, Spencer EM, Clinical Ethics History, Content, and Resources in Introduction to Clinical Ethics, (2nd Edition), Fletcher JC, Lombardo P, Marshall M, and Miller F, (Eds)., 3-20, Maryland: University Publishing; 1997

${ }^{16}$ Jonson AR, The Birth of Bioethics New York and Oxford: Oxford University Press; 1998, at p. 366.

17 Thomasma DC, Clinical Ethics as Medical Hermeneutics, Theoretical Medicine, 1994, 15, 93111.

${ }^{18}$ La Puma J, Schiedermayer D, Ethics Consultation: Skills, Roles, and Training Annals of Internal Medicine, 1991, 114, 2, 155-160, at p. 155.

${ }_{19}$ La Puma J, Schiedermayer D, Ethics Consultation: A Practical Guide, Boston \& London: Jones and Bartlett Publishers; 1994, at p. 60

${ }^{20}$ Murray TH, Where are the Ethics in Ethics Committees? Hastings Center Report, 1988, FebMarch, 12-13, at p. 12

${ }^{21}$ Singer PA, Siegler M, Pellegrino ED, Research in Clinical Ethics, Journal of Clinical Ethics, 1990, 1, 2, 95-98, at p. 95.

22 Zaner RM, Ethics and the Clinical Encounter, Ohio: Academic Renewal Press; 2003, at p. 5

${ }^{23}$ Sulmasy DP, On the Current State of Clinical Ethics, Pain Medicine, 2001, 2, 2, 97-105, at p.

97.

${ }^{24}$ d'Oronzio JC, Dunn D, Gregory J, A Survey of New Jersey Hospital Ethics Committees, HEC Forum, 1991, 3, 5, 255-268;

${ }^{25}$ Milmore D, Hospital Ethics Committees: A Survey in Upstate New York, HEC Forum, 2006, $18,222-244$, at p.229

${ }^{26}$ Hoffmann D, Tarzian A., O'Neill A, Are Ethics Committees Members Competent to Consult? Journal of Law, Medicine and Ethics, 2000, 28, 30-40.

27 See http://www3.imperial.ac.uk/cpd/courses/subject/medical/ace/ and

http://www.ethox.org.uk/ethics-support [accessed on 20 April 2007]

${ }^{28}$ MacIntyre A, Patients as Agents, Philosophical Medical Ethics: It's Nature and Significance, 197212, Spinker SF, Engelhardt HT, (Eds) Boston and Dordrecht: Reidel; 1977.

29 Beauchamp TL, Does Ethical Theory Have a Future in Bioethics? Journal of Law, Medicine and Ethics, 2004, 32, 276-278.

${ }^{30}$ Downie RS, Macnaughton J, Bioethics and the Humanities: Attitudes and Perceptions, London: Routledge/Cavendish; 2007.

${ }^{31}$ Hedgecoe AM, Critical Bioethics: Beyond the Social Science Critique of Applied Ethics. Bioethics, 2004, 18, 2, 120-142

${ }^{32}$ De Vries R, How Can we Help? From "Sociology in" to "Sociology of" Bioethics, Journal of Law, Medicine and Ethics, 2003, 32, 279-292 
33 Schneidermann LJ, Gilmer T, Teetzel HD, Impact of Ethics Consultations in the Intensive Care Setting: A Randomized, Controlled Trial. Critical Care Medicine, 2000, 28, 12, 3920-3924.

${ }^{34}$ La Puma J, Stocking CB, Darling C, Siegler M, Community Hospital Ethics Consultation: Evaluation and Comparison with a University Hospital Service. American Journal of Medicine, 1992, 92, April 346-351.

${ }^{35}$ Williamson L, Empirical Assessments of Clinical Ethics Services: Implications for Clinical Ethics Committees. Clinical Ethics, 2007 (In Press). 